\section{RNAi Nobel ignores vital groundwork on plants}

\section{SIR — The Nobel prize, by recognizing} the individuals behind breakthroughs, inspires all scientists to do great science. The discovery of RNA interference (RNAi) changed the face of gene regulation, a feat deservedly recognized with this year's Nobel Prize in Physiology or Medicine ${ }^{1}$.

As undergraduates, we witnessed with great excitement the discovery of gene silencing. At that time, almost all research in that area was being conducted by plant scientists, and as young plant biologists we were lucky to have front-row seats to this molecular drama.

Like all great advances, RNAi is turning out to be important in ways that could not have been guessed at even a decade ago. Therefore we were not surprised to discover that the topic was selected for this year's honour but we were shocked that the plant scientists who were so crucial in discovering and communicating the underlying mechanism of RNAi were not awarded a share.

Of course there is often controversy around the awarding of the Nobel prize. Yet in this case we feel that a grave error has been made in overlooking key researchers, all of whom work on plants. Most of the six points cited in support of the prize were not first shown by Andrew Fire or Craig Mello, who won the prize, but were already known from plant research. For example, the sequence specificity, RNA degradation and post-transcriptional nature of gene silencing had all been shown in studies on plants and plant viruses ${ }^{23}$. In addition, the observation that silencing is non-cell-autonomous was first done in plants ${ }^{4}$. Moreover, the models involving double-stranded RNA and amplification mechanisms had been proposed by plant researchers before the publications of RNAi mechanisms in animal systems ${ }^{5}$.

In our view, the main importance of the work by Fire, Mello and colleagues (accessible via ref. 1., together with other relevant articles) was the integration of these elements to demonstrate that they stood up to testing in an animal system, the nematode worm Caenorhabditis eleyans. Subsequently, plant research continued to break new ground on mechanisms of RNAi-based genetic regulation.

As the Nobel prize may be shared by three people, a plant scientist should have been included. One who springs to mind as a pioneer in the field is David Baulcombe (see www.sainsbury-laboratory.ac.uk/dcb). His work was key to understanding the mechanism of RNAi and paved the way for Fire and Mello's findings.

By ignoring the work done in plants, the Nobel committee has undermined the values at the centre of the prize and is sending a discouraging message, especially to young researchers.

Marc Bots*, Spencer Maughan $\dagger$,

Jeroen Nieuwlandt

*Flanders Intenuniversity Institute for Biotechnology, Technologiepark 927, BE-9052 Gent, Belgium †Institute of Biotechnology, University of Cambridge, Cambridge CB2 1QT, UK

1. Nature $443,488(2006)$

2. Baulcombe, D.C. Plant Mal. Biol. 32, 79-88 (1996).

3. Van der Krol, A. R et al. Plant Cell 2, 291-299(1990).

4. Voinnet, Q \& Baulcombe, D. C Nature 389,553 (1997).

5. Metzlaff, M, O'Dell, M, Cluster, P.D. \& Plavell, R.B.Cell 88, 845-854 (1997).

\section{Iran seeks nuclear power to replace reliance on oil}

SIR - I read with interest your Editorial “Revival in Iran" about the development of the country's education and science (Nature $442,719-720 ; 2006)$. As you say, Iran made many achievements during the time of Nizam al-Mulk. Its history also includes many other periods in which highly qualified scientists such as Razi in the ninth century and Avicenna in the tenth made great advances.

You suggest that Iran's desire for nuclear technology may have served as an impetus for its rise in science, and that this programme is viewed with suspicion by many. It is not clear to me why you doubt that growth in science will be maintained. The acquisition and use of technology, including nudear, is a major item of Iranian scientists' agenda, in the hope that nuclear power can replace oil as the country's main source of energy.

Your Editorial states that more than 4,000 papers from Iranian scientists were published in 2005. In fact, ISI indicates that 5,576 papers were published in 2005, compared with 4,343 so far in 2006: a figure likely to rise to about 6,500 by the end of the year - a $17 \%$ increase. If research into medical and related sciences is considered separately, Medline indicates that 1,466 Iranian papers were published in 2005, whereas for 2006 to date the figure is 1,440 and likely to rise to about 2100 by the end of the year: an increase of $46 \%$. The trend of scientific progress is certain to be maintained and the " worryingly inexperienced people ${ }^{n}$ appointed to lead the universities will steer Iran to new horizons. The average qualification of these new incumbents is higher than their predecessors' - the latter were well qualified, but even better-qualified people are now available. The outgoing presidents have become members of national decision-making bodies, for example the health policy council, and sit on universities' boards of trustees. Rather than their experience being lost, it is used to help exchange views with the new appointees.

Iran has not faltered in maintaining its momentum for contributing to science, and will not do so in the future. We believe that Iranian scientists can and will respond appropriately to the country's needs. Kamran B. Lankarani Ministry of Health and Medical Education of L. R. Iran, Tehran, L. R. Iran

\section{Iran: productivity is not simple to evaluate}

SIR - Eran Meshorer, in Correspondence ("Iran is sixth, not second, in Middle East publication list" Nature 443, 271;2006), states: ${ }^{\circ}$ When the number of publications (see www. ncbi.nlm.nih.gov/entrez) is corrected for population size, Iran becomes only the sixth in terms of scientific productivity. However, the scientific productivity of a country is not the number of publications divided by the number of people. To evaluate productivity, one has to account for other important factors, such as publication citations. In addition, the NCBI website is mainly devoted to life-sciences journals and does not cover the main journals in other fields.

We can usually use our common sense to evaluate a country's scientific productivity from what we can observe of its output: an article at http://en.wikipedia.org/wiki/ Science_in_Iran gives some background. But if a more systematic approach is desired, it is certain that there is no single formula that can provide a definitive ranking.

Hamid Reza Maei

Department of Physiology, University of Toranto, Toranto, Ontario M5S 1A8, Canada

\section{Iran: let's keep politics in the realm of rationality}

SIR - I read with interest the debate about Iran's scientific development in your Editorial and Correspondence (Nature 442, 719-720 and 443,$271 ; 2006)$. The Correspondence authors argued that Iran poses a danger. However, I believe that, as scientists, we have a duty to remain rational, believing in facts and distrusting rhetoric - whether from Iran, the United States or elsewhere.

I do not believe that evidence has been produced to show Iran's nuclear-technology programme is being used for military purposes. By relying on words, and hence on belief rather than evidence, we would elevate diplomacy and politics to the level of faith, whereas history teaches us that they should be kept in the realm of rationality. Francisco Goya told us in a famous etching that "the sleep of reason produces monsters". Let's not make that picture into a prophecy.

Ludovico Cademartiri

Department of Chemistry, University of Toronto, Toranto, Ontario M5S 3H6, Canada 